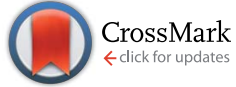

Cite this: RSC Adv., 2016, 6, 58443

Received 16th April 2016

Accepted 10th June 2016

DOI: 10.1039/c6ra09841j

www.rsc.org/advances

\section{Microwave-assisted methylation of dihydroxybenzene derivatives with dimethyl carbonate $\dagger$}

\author{
Matthew Y. Lui, ${ }^{a}$ Kapil S. Lokare, ${ }^{b}$ Ellen Hemming, ${ }^{a}$ Jessica N. G. Stanley, ${ }^{c}$ \\ Alvise Perosa, ${ }^{d}$ Maurizio Selva, ${ }^{d}$ Anthony F. Masters ${ }^{a}$ and Thomas Maschmeyer*ae
}

Using a focused microwave reactor, methylation with dimethyl carbonate (DMC) of 1,2- and 1,4dihydroxybenzene derivatives, found in the product spectrum of lignin depolymerisation, leads to the respective aromatic bis-methyl ethers with excellent isolated yields. Stoichiometric as well as catalytic amounts of 1,8-diazabicyclo[5.4.0]undec-7-ene (DBU) are effective for the bis-methylation of these dihydroxybenzenes at relatively mild temperatures $\left(160-190{ }^{\circ} \mathrm{C}\right)$. Conversion of resorcinol $(1,3-$ dihydroxybenzene) under similar conditions leads to a mixture of 1,3-dimethoxybenzene and methyl 2,4dimethoxybenzoate. The unusual reactivity of resorcinol's phenyl ring towards DMC can be explained by the synergic effect of its two strongly activating ortho/para directing groups.

\section{Introduction}

Dimethyl carbonate (DMC) has been described as a green reagent and solvent., ${ }^{\mathbf{1} 2}$ It can be prepared as a non-toxic compound via phosgene-free routes, including catalytic oxidative carbonylation reactions and $\mathrm{CO}_{2}$ cycloaddition to epoxides combined with transesterification. ${ }^{3-5}$ DMC exhibits a versatile reactivity, which makes it a candidate for the replacement of highly noxious chemicals such as phosgene, dimethyl sulfate (DMS) or methyl iodide (MeI) in catalytic methoxycarbonylation and methylation protocols ${ }^{\mathbf{1 , 6}}$ (Scheme 1).

A detailed comparison of model methylations of O-, C- and $\mathrm{N}$-nucleophiles has proven that DMC-mediated reactions are not only safer and more atom economic, but they are also advantageous in terms of mass index with respect to processes using DMS or MeI. ${ }^{7}$ DMC may also be preferred over methanol for alkylation reactions: in this case, the choice is mainly dictated by other features, particularly the non-toxicity of DMC

\footnotetext{
${ }^{a}$ Laboratory of Advanced Catalysis for Sustainability, School of Chemistry F11, The University of Sydney, Sydney, 2006, Australia. E-mail: thomas.maschmeyer@sydney. edu.au; Tel: +61293512581

${ }^{b}$ Humboldt-Universität zu Berlin, Institut für Chemie, Brook-Taylor-Str. 2, 12489 Berlin, Germany

'School of Chemical Engineering, The University of New South Wales, Sydney, NSW 2052, Australia

${ }^{d}$ Department of Molecular Sciences and Nanosystems, Centre for Sustainable Chemical Technologies, Università Ca'Foscari, Venezia, Italy

${ }^{e}$ Australian Institute for Nanoscale Science and Technology, The University of Sydney,
} NSW 2006, Australia

$\dagger$ Electronic supplementary information (ESI) available. See DOI: 10.1039/c6ra09841j and the relatively lower alkylating temperatures $\left(160-250{ }^{\circ} \mathrm{C}\right.$ for DMC versus $>320{ }^{\circ} \mathrm{C}$ for $\left.\mathrm{MeOH}\right){ }^{7}$

The technique of microwave heating has become a valuable method for the synthesis of organic compounds. Traditional heating techniques (e.g. oil baths on hot plates) are not always the most effective method to transfer energy to the reactants of a reaction mixture, especially since they depend on the thermal conductivity of the various materials that must be permeated. ${ }^{8}$ Conversely, with microwave heating, molecules in a reaction mixture might be efficiently heated internally by the direct coupling of energy from microwave irradiation. Furthermore, modern microwave instruments allow for precise temperature control, ${ }^{8}$ as well as enabling reaction mixtures to be superheated in a closed vessel. The latter feature is particularly useful for alkylation processes with DMC, as it allows the operating temperatures for these reactions to be considerably higher than DMC's boiling point $\left(90^{\circ} \mathrm{C}\right)$, reducing the reaction time. It is however accepted by the majority of scientists that a nonthermal microwave effect does not exist. ${ }^{9}$

In the specific case of $O$-methylation reactions, most of the DMC-based procedures use simple alcohols and phenols as substrates. ${ }^{10}$ Both conventional and microwave heating techniques have been employed for the methylation of phenols.

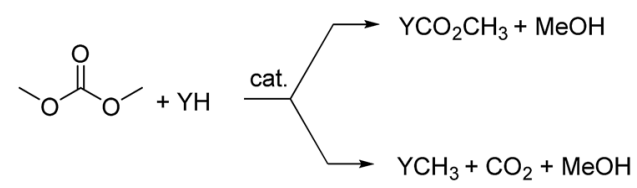

Scheme 1 Catalytic methoxycarbonylation and methylation reaction of a generic nucleophile $\mathrm{YH}$ with DMC (top and bottom, respectively). 
Tundo et al. reported the conversion of simple phenols with DMC in the presence of $\mathrm{K}_{2} \mathrm{CO}_{3}$ under reflux conditions $\left(90^{\circ} \mathrm{C}\right)$ for 53 hours. ${ }^{11}$ The conversion rate was very slow and in most cases a mixture of methylation and carboxymethylation products was formed. Lee et al. described the methylation of phenol with DMC in the presence of $\mathrm{Cs}_{2} \mathrm{CO}_{3}$ in a sealed tube at 120 ${ }^{\circ} \mathrm{C} .{ }^{\mathbf{1 0 b}}$ Using this method, 1-naphthol was completely methylated after 4 hours of heating. On the other hand, Glasnov et al. reported the microwave-assisted methylation of 4-nitrophenol and 4-fluorophenol with DMC using tributylmethylammonium methyl carbonate, which could be generated in situ with tributylamine, as the catalyst. ${ }^{10 k}$ The process was efficient and gave high yields of the $O$-methylation products under flow microwave conditions. The procedure, however, required the use of high temperatures and pressures $\left(285^{\circ} \mathrm{C}\right.$ and $\left.150 \mathrm{bar}\right)$, which could be detrimental to operational safety. On the other hand, only a few examples have been described for the methylation of dihydroxybenzenes (DHBs) with DMC. These compounds (DHBs) and the corresponding ethers are of major interest as intermediates for cosmetics and pharmaceuticals. Moreover, studies on the synthetic potential of DHBs and their derivatives are further fueled by the fact that such aromatics are building blocks of the lignin scaffold. In fact, lignin depolymerisation mainly affords catechol, ${ }^{12}$ but also several other DHBs including hydroquinone, ${ }^{\mathbf{1 3 , 1 4}}$ resorcinol, ${ }^{15}$ 4-methylcatechol, ${ }^{16-21}$ 4-ethylcatechol, ${ }^{17,18}$ methylhydroquinone ${ }^{16,22}$ and dimethylhydroquinone. ${ }^{23,24}$ It is noteworthy that the corresponding methyl ethers of all these compounds find application across a remarkable range as solvents and synthetic intermediates for the production of fragrances, cosmetics, pharmaceuticals and fuel additives. ${ }^{25}$

The $O$-alkylation of DHBs with DMC currently requires very high temperatures. For example, the continuous-flow alkylation of both catechol and hydroquinone with DMC was reported over supported $\mathrm{KOH}$ catalysts at $280{ }^{\circ} \mathrm{C}^{.26}$ under such conditions, mixtures of mono- and bis- $O$-methyl derivatives are observed. Ono and co-workers also reported the reaction of catechol with DMC in the gas phase at $320^{\circ} \mathrm{C}$, yielding guaiacol or veratrole (mono- and bis-methyl ether products, respectively) in the presence of $\mathrm{CsOH} / \mathrm{Al}_{2} \mathrm{O}_{3}$ or $\mathrm{KX} / \mathrm{Al}_{2} \mathrm{O}_{3}\left[\mathrm{X}=\mathrm{NO}_{3}{ }^{-}, \mathrm{HCO}_{3}{ }^{-}\right.$, $\left.\left(\mathrm{CO}_{3}{ }^{-}\right)_{(1 / 2)}\right]$ as catalysts. ${ }^{27 d, e}$ The same process was also investigated over $\mathrm{MgO}$-based catalysts between 250 and $320{ }^{\circ} \mathrm{C}$, where a $\sim 70 \%$ selectivity towards guaiacol was achieved. ${ }^{27 i}$ In general, other procedures always afforded mixtures of mono- and bis- $O$ methyl products, with the occasional formation of mono- $C$ methyl derivatives. ${ }^{27}$

Alternative methods for the alkylation of DHBs may be more selective towards the corresponding bis-methyl ethers, but they resort to the use of hazardous reagents such as MeI, ${ }^{28} \mathrm{DMS},{ }^{29}$ and methanol, ${ }^{30}$ or even the explosive $\mathrm{N}, \mathrm{N}$-dimethylformamidedimethylacetal (DMF-DMA). ${ }^{31}$ In this context, the design of a safe and efficient strategy for the syntheses of such ethers is a highly desirable target and it becomes even more attractive from the perspective of using not only biomass-derived aromatics, but also mild reaction conditions to optimise the product distribution. As part of a program on green methodologies for the upgrading of renewables, we have recently approached this problem by reporting on the reaction of DMC with 4-(3-hydroxypropyl)phenol, in the presence of several inorganic- and organo-catalysts including $\mathrm{K}_{2} \mathrm{CO}_{3}, \mathrm{CsF} / \alpha-\mathrm{Al}_{2} \mathrm{O}_{3}$, alkali metal-exchanged faujasites, and trioctylmethylphosphonium methyl carbonate $\left(\left[\mathrm{P}_{8881}\right]\left[\mathrm{CH}_{3}\right.\right.$ OCOO]), respectively. ${ }^{32}$ Although a good alkylation selectivity (>80\%) was obtained, the reaction took place only at $T \geq 180^{\circ} \mathrm{C}$, requiring the use of steel autoclaves under an autogenous pressure of 6-10 bar.

Here, we describe that the $O$-methylation of three models of DHBs such as catechol, resorcinol, and hydroquinone, has been achieved with dimethyl carbonate by using a focused microwave system under liquid-phase conditions. This is a largely unexplored area with only a very few papers describing microwaveassisted methylation of just the simple (mono)-phenols by DMC using 1,8-diazabicyclo[5.4.0]undec-7-ene (DBU) as a catalyst in MeCN, DMF, or sulfolane solvents. ${ }^{\mathbf{1 0}-\mathrm{g}}$

This work elucidates paths towards not only a significant decrease of reaction times (down to minutes from the hours for conventionally heated processes), but it also improves selectivity, safety and facilitates a more convenient separation of products - all working together to enhance the 'green' character of this type of conversion.

\section{Materials and methods}

\section{General}

All reactions were carried out in air. DMC, mesitylene, catechol, 4-methylcatechol, 4-ethylcatechol, methylhydroquinone, dimethylhydroquinone, DBU, DABCO and $\mathrm{Cs}_{2} \mathrm{CO}_{3}$ (Aldrich) resorcinol, pyridine, $\mathrm{K}_{2} \mathrm{CO}_{3}$ and $\mathrm{KOH}$ (Ajax), triethylamine (Merck) hydroquinone (Alfa Aesar) and catechol carbonate (Oxchem) were used without purification.

Quantification of the reaction products was performed on a Shimadzu GC-2010 Plus gas chromatograph equipped with Rtx-5MS $0.25 \mu \mathrm{m} \times 30 \mathrm{~m} \times 0.25 \mathrm{~mm}$ column under the following conditions. The temperature program had an isothermal period of $1 \mathrm{~min}$ at $50{ }^{\circ} \mathrm{C}$, then the temperature was increased by $15^{\circ} \mathrm{C} \mathrm{min}{ }^{-1}$ to another isothermal period of $4 \mathrm{~min}$ at $250{ }^{\circ} \mathrm{C}$. Compounds of interest were quantified using calibration curves of authentic samples. In some cases, compounds were quantified by ${ }^{1} \mathrm{H}$ NMR analysis. NMR spectra were collected using a Bruker $300 \mathrm{MHz}$ instrument at about $300 \mathrm{~K}$ after 16 scans. ${ }^{1} \mathrm{H}$ NMR spectra were obtained using a $90^{\circ}$ flip angle with a recycle delay (D1) of 100 seconds. Compound identification by GC-MS was performed on a Shimadzu GCMSQP2010 equipped with Rtx-5MS $0.25 \mu \mathrm{m} \times 30 \mathrm{~m} \times 0.25 \mathrm{~mm}$ column under the following conditions. The temperature program had an isothermal period of $3 \mathrm{~min}$ at $50{ }^{\circ} \mathrm{C}$. Then the temperature was increased by $10{ }^{\circ} \mathrm{C} \min ^{-1}$ to another isothermal period of $10 \mathrm{~min}$ at $330{ }^{\circ} \mathrm{C}$. Compounds were identified by comparing the EI-MS spectrum with the MS library NIST05. The Anton Paar Monowave 300 microwave synthesis reactor used in the experiments below has the following specifications, magnetron frequency, $2455 \mathrm{MHz}$; power consumption, $1600 \mathrm{VA}$; and an AC $230 \mathrm{~V} \pm 10 \% 50 \mathrm{~Hz} / 60 \mathrm{~Hz}$ power supply. 


\section{Determination of vapor pressure of DMC}

A batch reactor $(245 \mathrm{~mL}$ internal volume, Parr Instrument Company, modified with the inclusion of a second external thermocouple) was charged with DMC (60 mL, $0.71 \mathrm{~mol})$. The reactor was purged with $\mathrm{N}_{2}$ and pressurised to $6760 \mathrm{mbar}$ with $\mathrm{N}_{2}$. The reactor was heated stepwise in integral control mode under continuous stirring, holding the temperature at each of the chosen set-points (below) for $10 \mathrm{~min}$, to allow for equilibration. The heating steps were: $22.6{ }^{\circ} \mathrm{C}-$ hold $-80{ }^{\circ} \mathrm{C}-$ hold $140{ }^{\circ} \mathrm{C}$ - hold $-160{ }^{\circ} \mathrm{C}$ - hold $-180^{\circ} \mathrm{C}$ - hold $-220^{\circ} \mathrm{C}$ - hold -230 ${ }^{\circ} \mathrm{C}$ - hold $-240{ }^{\circ} \mathrm{C}$ - hold. The reactor pressure was recorded approximately every $10 \mathrm{~min}$. The measurement series was performed twice and the data sets combined.

\section{Methylation of catechol, hydroquinone and resorcinol with DMC at various temperatures under microwave conditions}

A solution of substrate $(2.73 \mathrm{mmol})$, DBU (5.46 mmol), DMC (3 $\mathrm{mL}$ ), and MeCN (3 mL) was heated in a $30 \mathrm{~mL}$ air tight glass vessel in an Anton Paar Monowave 300 microwave synthesis reactor at temperature " $T$ " ${ }^{\circ} \mathrm{C}$ with a stirring rate of $600 \mathrm{rpm}$. After 40 minutes, the reaction vial was removed from the microwave reactor and cooled to room temperature. The mixture was concentrated at $40{ }^{\circ} \mathrm{C}$ and $98 \mathrm{mbar}$, and mesitylene $(200 \mu \mathrm{L})$ added as an external standard. The mixture was then combined with $1 \mathrm{M} \mathrm{HCl}(7.5 \mathrm{~mL})$ and magnesium chloride hexahydrate $(7.7 \mathrm{M}, 7.5 \mathrm{~mL})$. The organic layer was subsequently extracted with ethyl acetate $(10 \times 2 \mathrm{~mL})$, dried over anhydrous sodium sulfate and filtered. The sample was then analysed by ${ }^{1} \mathrm{H}$ NMR, GC-FID and GC-MS.

\section{Methylation of catechol with various amounts of DMC under microwave conditions}

A solution of catechol (2.73 mmol), DBU (5.46 mmol), MeCN (3 $\mathrm{mL}$ ) and various amount of DMC was heated in a $30 \mathrm{~mL}$ air tight glass vessel in an Anton Paar Monowave 300 microwave synthesis reactor at temperature of $160{ }^{\circ} \mathrm{C}$ with a stirring rate of $600 \mathrm{rpm}$. After 40 minutes, the reaction vial was removed from the microwave reactor and cooled to room temperature. The mixture was concentrated at $40{ }^{\circ} \mathrm{C}$ and $98 \mathrm{mbar}$, and mesitylene $(200 \mu \mathrm{L})$ added as an external standard. The mixture was then combined with $1 \mathrm{M} \mathrm{HCl}(7.5 \mathrm{~mL})$ and magnesium chloride hexahydrate $(7.7 \mathrm{M}, 7.5 \mathrm{~mL})$. The organic layer was subsequently extracted with ethyl acetate $(10 \times 2 \mathrm{~mL})$, dried over anhydrous sodium sulfate and filtered. The sample was then analysed by GC-FID and GC-MS.

\section{Methylation of catechol, hydroquinone and resorcinol with DMC using catalytic amounts of DBU under microwave conditions}

A solution of substrate $(2.73 \mathrm{mmol})$, a catalytic amount of DBU, DMC ( $3 \mathrm{~mL})$ and MeCN (3 mL) was heated in a $30 \mathrm{~mL}$ air tight glass vessel in an Anton Paar Monowave 300 microwave synthesis reactor at different temperatures with a stirring rate of $600 \mathrm{rpm}$. After 80 minutes, the reaction vial was removed from the microwave reactor and cooled to room temperature. The mixture was concentrated at $40{ }^{\circ} \mathrm{C}$ and $98 \mathrm{mbar}$, and mesitylene $(200 \mu \mathrm{L})$ added as an external standard. The mixture was then combined with $1 \mathrm{M} \mathrm{HCl}(7.5 \mathrm{~mL})$ and magnesium chloride hexahydrate $(7.7 \mathrm{M}, 7.5 \mathrm{~mL})$. The organic layer was subsequently extracted with ethyl acetate $(10 \times 2 \mathrm{~mL})$, dried over anhydrous sodium sulfate and filtered. The sample was then analysed by ${ }^{1} \mathrm{H}$ NMR, GC-FID and GC-MS.

\section{Methylation of various dihydroxybenzenes using the focused microwave}

A glass tube $(30 \mathrm{~mL})$ was loaded with a stirrer bar, substrate (2.73 mmol), DBU (5.46 mmol), DMC (3 mL) MeCN (3 mL). The tube was then fitted with a Teflon cap, and heated at the assigned temperature for the requisite time in an Anton Paar Monowave 300 microwave synthesis reactor with a stirring rate of $600 \mathrm{rpm}$. After heating was completed, the pressure tube was removed from the microwave reactor and cooled to room temperature, and the volatiles were removed in vacuo. The mixture was then combined with $1 \mathrm{M} \mathrm{HCl}(7.5 \mathrm{~mL})$ and magnesium chloride hexahydrate $(7.7 \mathrm{M}, 7.5 \mathrm{~mL})$. The organic layer was subsequently extracted with ethyl acetate $(3 \times 10 \mathrm{~mL})$. The organic fractions were combined and concentrated. The product mixture was purified by column chromatography on silica gel. The chromatography was carried out using mixtures of hexane/diethyl ether (from 100\% hexane to $7: 3 \mathrm{v} / \mathrm{v}$ hexane/ diethyl ether) as eluents.

\section{Methylation of catechol carbonate with DMC under microwave conditions}

A solution of catechol carbonate $(0.91 \mathrm{mmol})$, various amounts of DBU and methanol, DMC (1 mL), and MeCN (1 mL) was heated in a $10 \mathrm{~mL}$ air tight glass vessel in an Anton Paar Monowave 300 microwave synthesis reactor at $160{ }^{\circ} \mathrm{C}$ with a stirring rate of $600 \mathrm{rpm}$. The reaction vial was removed from the microwave reactor and cooled to room temperature. The mixture was concentrated at $40{ }^{\circ} \mathrm{C}$ and $98 \mathrm{mbar}$, and mesitylene $(100 \mu \mathrm{L})$ added as an external standard. The mixture was then combined with $1 \mathrm{M} \mathrm{HCl}(7.5 \mathrm{~mL})$ and magnesium chloride hexahydrate $(7.7 \mathrm{M}, 7.5 \mathrm{~mL})$. The organic layer was subsequently extracted with ethyl acetate $(10 \times 2 \mathrm{~mL})$, dried over anhydrous sodium sulfate and filtered. The sample was then analysed by GC-FID and GC-MS.

\section{Synthesis of methyl 4-hydroxy-2-methoxybenzoate (compound} 6)

Methyl 4-hydroxy-2-methoxybenzoate was synthesised following a procedure $^{33}$ reported previously.

\section{Results and discussion}

Methylation reactions involving DMC are typically performed at temperatures $\geq 160{ }^{\circ} \mathrm{C}$, i.e. much higher than its boiling point $\left(90{ }^{\circ} \mathrm{C}\right)$. The knowledge of the vapour pressure of DMC is therefore important for the design and safe operation of such reactions. However, few of such data are available in the 
literature, referring only to a narrow temperature range below $155{ }^{\circ} \mathrm{C} .{ }^{34}$

As the first part of this investigation, measurements of the vapour pressure of DMC were carried out from ambient to high temperatures under isochoric conditions: in particular, the total pressure in a batch reactor containing $\mathrm{N}_{2}$ and DMC was determined across the range of 22.6 to $240{ }^{\circ} \mathrm{C}$ (295.75 to $\left.513.15 \mathrm{~K}\right)$.

The vapour pressures of DMC as a function of varying temperature were fitted to the integrated form of the ClausiusClapeyron equation (eqn (1)):

$$
\ln P=-\frac{-\Delta H_{\text {vap }}}{R}\left(\frac{1}{T}\right)+C
$$

where $P$ is the vapour pressure $(\mathrm{kPa}), T$ is the absolute temperature (K), $\Delta H_{\text {vap }}$ is the enthalpy of vapourisation (kJ $\left.\mathrm{mol}^{-1}\right), R$ is the gas constant $\left(=8.314 \mathrm{~J} \mathrm{~mol}^{-1} \mathrm{~K}^{-1}\right)$, and $C$ is a constant.

Eqn (1) assumes that the enthalpy of vapourisation is constant across the entire temperature range. Furthermore, DMC is assumed to behave as an ideal gas. The fit of the data indicates sufficient linearity to render these assumptions valid for the purposes discussed here ( $c f$. Fig. 1 the plot of $\ln (P / \mathrm{kPa})$ vs. $10^{3} \mathrm{~T} / \mathrm{K}^{-1}$ with a straight fit and an R-squared value of 0.91 ).

To verify the reliability of the measurements obtained, and the appropriateness of using the Clausius-Clapeyron equation for the system investigated, the enthalpy of vapourisation over the experimental temperature range was determined from the fit as $36.6 \pm 3.4 \mathrm{~kJ} \mathrm{~mol}^{-1}$ ( $2 \sigma$ error). This is in excellent agreement with those reported in the literature by both Steele et al. $\left(37.7 \mathrm{~kJ} \mathrm{~mol}^{-1} \text { at } 25^{\circ} \mathrm{C}\right)^{35}$ and Walker $\left(37.3 \mathrm{~kJ} \mathrm{~mol}^{-1}\right.$ at $\left.25^{\circ} \mathrm{C}\right) .^{36}$

This result confirmed that DMC was stable under the conditions examined. Although the data were not obtained under perfect equilibrium conditions, the excellent fit with the literature values reported for lower temperature ranges, suggests that the approximation to equilibrium conditions is acceptable. These results can serve as an empirically based guide to the planning and assessment of reactions of DMC

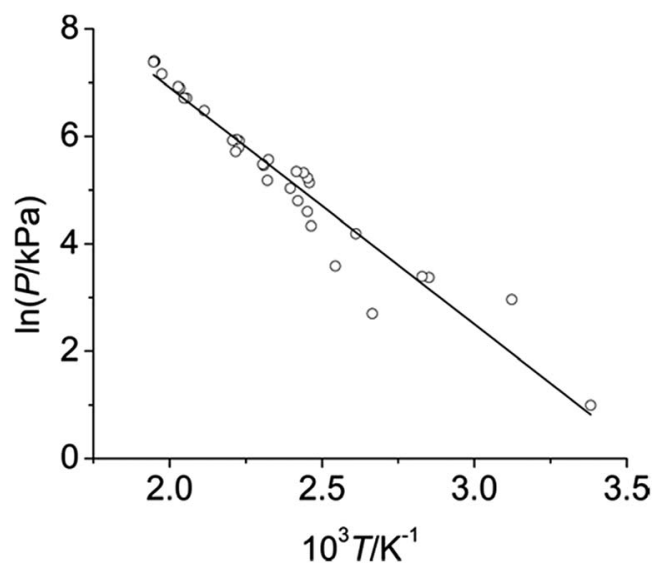

Fig. 1 Graph of $\ln (P / \mathrm{kPa})$ versus $10^{3} T / \mathrm{K}^{-1}$, combining data sets from the two measurements. Raw data shown as open circles, fitted data using eqn (1), see above, shown as solid line. across an extended temperature range - something that is currently absent in the literature.

\section{Phenol as substrate}

To rank our system's performance, initially we investigated the well-established methylation of phenol with DMC, which was carried out in a focused microwave as a screening test for a number of common, commercially available bases. Of all the bases tested, DBU afforded almost complete conversion of phenol within $20 \mathrm{~min}$ (93.2\%, Table S1, ESI $\dagger$ ) in MeCN as determined by GC-FID analysis (mesitylene as an internal standard). The exceptional activity of DBU shown here is consistent with the earlier reports by Tilstam under continuous flow, ${ }^{\mathbf{1 0} f, g}$ and Rajabi utilizing a conventional microwave oven. ${ }^{\mathbf{1 0 d}}$ Other bases examined include 1,4-diazabicyclo[2.2.2] octane (DABCO), triethylamine, pyridine, $\mathrm{KOH}, \mathrm{K}_{2} \mathrm{CO}_{3}$ and $\mathrm{Cs}_{2} \mathrm{CO}_{3}$ (Table S1, ESI $\dagger$ ). While DABCO afforded $85.3 \%$ yield, triethylamine afforded only a moderate yield, $14.1 \%$, and pyridine gave just $0.4 \%$ yield. Additionally, $\mathrm{KOH}, \mathrm{K}_{2} \mathrm{CO}_{3}$ and $\mathrm{Cs}_{2} \mathrm{CO}_{3}$ afforded 4.7, 6.2 and $63.7 \%$ yields respectively. The more soluble $\mathrm{Cs}_{2} \mathrm{CO}_{3}$ affords a significantly higher conversion as compared to less soluble bases such as $\mathrm{KOH}$ and $\mathrm{K}_{2} \mathrm{CO}_{3}$ in MeCN.

Attention was then switched to the less/unexplored DHBs such as catechol, hydroquinone and resorcinol.

Catechol. The results obtained with catechol are in line with those obtained for phenol. Fig. 2 shows the profile of GC yields of products observed in the reaction of catechol with DMC over the temperature range from $100-170{ }^{\circ} \mathrm{C}$. At higher temperatures of 160 and $170{ }^{\circ} \mathrm{C}$, the reaction of catechol afforded almost exclusively veratrole $(94.9 \%$ and $97.6 \%)$ with only traces of guaiacol after 40 minutes of heating. Conversely, at $140{ }^{\circ} \mathrm{C}$, guaiacol and veratrole were achieved in only 37.4 and $22.6 \%$ amounts, respectively. The optimal temperature for the selective bis-alkylation of catechol is therefore at about $160-170{ }^{\circ} \mathrm{C}$. To reduce operating pressures and heat involved, $160{ }^{\circ} \mathrm{C}$ was used for the conversion of catechol and its derivatives. For comparison, catechol was reacted with DMC at $160{ }^{\circ} \mathrm{C}$ in a stainless steel pressure tube using a conventional heating method (i.e. an oil bath) for 40 minutes to give slightly lower yield of veratrole $(91.0 \%)$ and a trace of guaiacol $(0.2 \%)$. In order to improve the mass balance accuracy during the product analysis and recovery stage, the reaction mixtures were acidified with aqueous $\mathrm{HCl}$ and added to a saturated solution of $\mathrm{MgCl}_{2}$ to favour extraction of phenolic compounds from the aqueous phase (extraction of catechol into the organic phase is particularly difficult since it has high solubility in water, $6.88 \mathrm{~mol} \%$ at $\left.20{ }^{\circ} \mathrm{C}\right) .{ }^{37}$ In contrast to previous studies under vapour phase conditions (280-310 ${ }^{\circ} \mathrm{C}$ with heterogeneous catalysts), ${ }^{27 b, c, e} C$ methylation products were not observed in our system.

Beside catechol, guaiacol and veratrole, traces of catechol carbonate $(<1 \%)$ were observed in some of the reaction mixtures. In particular, at $160{ }^{\circ} \mathrm{C}$, catechol carbonate was detected only in the early stage of the reaction. Although this compound has been reported as one of the intermediates in the conversion of catechol to veratrole, no mechanism has yet been suggested for this transformation. ${ }^{\mathbf{1 0 d}, \boldsymbol{e}, \boldsymbol{j}}$ 


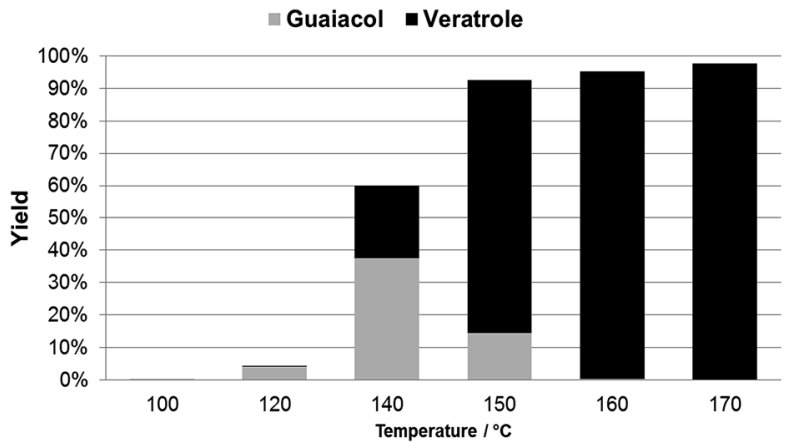

Fig. 2 Yield profile for mono- and bis-methylation of catechol (2.73 $\mathrm{mmol})$ with dimethyl carbonate $(3 \mathrm{~mL})$ in the presence of DBU $(5.46$ $\mathrm{mmol}$ ) and $\mathrm{CH}_{3} \mathrm{CN}(3 \mathrm{~mL})$. Reactions were carried out for $40 \mathrm{~min}$, in an Anton Paar 300 focused microwave, at $T$ of $100-170{ }^{\circ} \mathrm{C}$. Yield was determined by GC.

To explore this aspect, pure catechol carbonate was set to react under conditions similar to those used for catechol (with and without methanol). Excellent yields of veratrole were obtained (Table 1). Recognising that an equilibrium between DBU, DMC and the methoxide ion is established (Fig. 3, frame window, top), ${ }^{38,39}$ a plausible mechanism for the formation of veratrole is illustrated at the bottom of Fig. 3: an initial transesterification promoted by $\mathrm{CH}_{3} \mathrm{O}^{-}$is followed by intramolecular decarboxylation producing the anion (ii); this is then methylated either by DMC or the $\mathrm{N}$ methoxycarbonylated salt of DBU (i) (paths a and b, respectively).

Alternatively, DBU could also undergo direct nucleophilic attack on the catechol carbonate (Fig. 4). This opens up the carbonate ring and frees a phenoxide ion for reaction with the methylating agent (i.e. the $N$-methoxycarbonyl-amidinium adduct in Fig. 3). Then transesterification of the resulting intermediate by the methoxide ion releases free DBU and generates 2-methoxyphenyl methyl carbonate, which reacts with DBU to form the $N$-methoxycarbonyl-amidinium cation and guaiacyl anion. Subsequently, the two ionic species react to produce veratrole.

The methylation of catechol was then investigated in the presence of other bases. Results followed a trend similar to that observed for phenol (Table 2): at $170{ }^{\circ} \mathrm{C}, \mathrm{Cs}_{2} \mathrm{CO}_{3}$ was not as

Table 1 Results of conversion of catechol carbonate with DBU (1.82 $\mathrm{mmol}), \mathrm{DMC}(1 \mathrm{~mL})$ in $\mathrm{CH}_{3} \mathrm{CN}(1 \mathrm{~mL})$ at $160^{\circ} \mathrm{C}$. The reaction mixtures were heated in an Anton Paar 300 focused microwave. Yield was determined by GC

\begin{tabular}{llllll}
\hline Entry & $\begin{array}{l}\text { Catechol } \\
\text { carbonate/mmol }\end{array}$ & $\begin{array}{l}\text { Methanol// } \\
\mathrm{mmol}\end{array}$ & $\begin{array}{l}\text { Time/ } \\
\mathrm{min}\end{array}$ & $\begin{array}{l}\text { Guaiacol/ } \\
\%\end{array}$ & $\begin{array}{l}\text { Veratrole/ } \\
\%\end{array}$ \\
\hline 1 & 0.91 & 0 & 16 & 16.4 & 41.7 \\
2 & 0.91 & 0 & 32 & 2.5 & 90.1 \\
3 & 0.91 & 0 & 64 & 0 & 93.0 \\
4 & 0.18 & 0 & 64 & 0 & 91.6 \\
5 & 0.91 & 1.82 & 64 & 0 & 94.2 \\
6 & 0.91 & 9.1 & 128 & 0 & 89.5
\end{tabular}


Fig. 3 One possible mechanism for the formation of veratrole from catechol carbonate (ring opened by methoxide).

active as DBU (compare entries 2, 3 and 4); while the use of DABCO resulted in the full conversion of catechol after 40 minutes, it was poorly selective due to the formation of unidentified by-products (entry 5).

Hydroquinone. The methylation of hydroquinone with DMC was investigated under conditions similar to those used for catechol. Excellent results were achieved: at $170{ }^{\circ} \mathrm{C}$, after heating for 40 minutes, hydroquinone was fully converted into the corresponding bis-methyl derivative, 1,4-dimethoxybenzene (96\%) (Table 2, entry 7).

Resorcinol. The reaction of resorcinol with DMC was also investigated at $170{ }^{\circ} \mathrm{C}$ in the presence of a stoichiometric amount of DBU (Table 2, entry 8). Unexpectedly, the major product was methyl 2,4-dimethoxybenzoate ( $7,65 \%$ yield), rather than 1,3-dimethoxybenzene $(35 \%$ yield $)$. It was noticed that when a mixture of resorcinol, DBU, and DMC in MeCN was heated for only 2 minutes, both methyl 2,4dihydroxybenzoate (4) and methyl 4-methoxysalicylate (5) were obtained along with the $O$-methylation derivatives 3 -

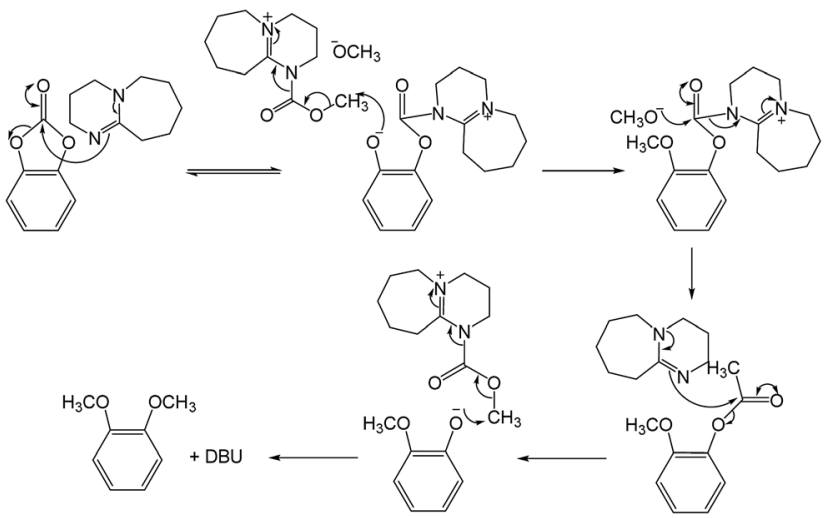

Fig. 4 Alternative mechanism for the formation of veratrole from catechol carbonate (ring-opened by DBU). 
Table 2 Results of mono- and bis-methylation of different dihydroxybenzenes ( $\mathrm{mmol}$ ) of different bases (1 equiv. per -OH) and DMC ( $3 \mathrm{~mL})$ in $\mathrm{CH}_{3} \mathrm{CN}(3 \mathrm{~mL})$. The reaction mixtures were heated for $40 \mathrm{~min}$ in an Anton Paar 300 focused microwave. Yield was determined by GC or ${ }^{1} \mathrm{H}$ NMR

\begin{tabular}{|c|c|c|c|c|c|c|}
\hline 1 & Catechol & DBU & 160 & 100 & 0.3 & 94.9 \\
\hline 3 & Catechol & $\mathrm{Cs}_{2} \mathrm{CO}_{3}$ & 170 & 100 & 23.0 & 57.4 \\
\hline $4^{a}$ & Catechol & $\mathrm{Cs}_{2} \mathrm{CO}_{3}$ & 170 & 100 & 8.1 & 70.3 \\
\hline 5 & Catechol & DABCO & 170 & 100 & 0 & 70.4 \\
\hline 8 & Resorcinol & DBU & 170 & 100 & 0 & 35.0 \\
\hline 9 & 0.5 Catechol +0.5 hydroquinone & DBU & 170 & 100 & 0 & $88.2+83.7$ \\
\hline
\end{tabular}

methoxyphenol (2) and 1,3-dimethoxybenzene (3). These products were all identified by GC-MS. A plausible mechanism for the formation of methyl 2,4-dimethoxybenzoate was then suggested via carboxymethylation of the phenyl ring shown in Fig. 5. Resorcinol (1) is initially deprotonated by DBU. Thereafter, the corresponding anion undergoes two possible reactions with DMC: (i) alkyl nucleophilic substitution (O-methylation) to produce compounds 2 and 3 (Fig. 5, top); (ii) electrophilic aromatic substitution on the activated phenyl ring to yield derivatives 4 and 5 (Fig. 5, bottom).

Of note, the methylation of $\mathbf{4}$ afforded only compound $\mathbf{5}$, but not even a trace of the isomer methyl 4-hydroxy-2methoxybenzoate (6, Fig. 5) was observed in the reaction mixtures, indicating that the hydroxy substituent para to the methyl ester group was more sterically accessible, than that in the ortho position. Then, only once 5 was formed, the subsequent methylation step took place, forming methyl 2,4dimethoxybenzoate (7, Fig. 5). No carboxymethylation of the phenyl rings was observed when either 3-methoxyphenol, 2, or 1,3-dimethoxybenzene, 3 , was heated under the same conditions, indicating that ring carboxymethylation, rather than oxo-methylation, of the resorcinolate dianion is

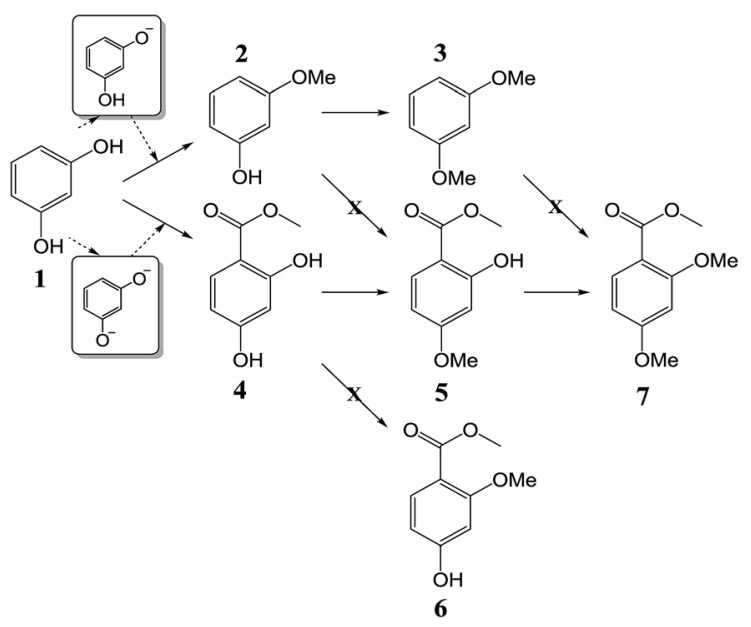

Fig. 5 Pathways of the reaction of resorcinol with DBU and DMC. preferred. When no DBU was added, resorcinol did not react. Hence, oxoanions, which are more activating than hydroxy groups, ${ }^{40,41}$ must be created for the carboxymethylation to occur.

After the electron-withdrawing methyl ester group was introduced to the phenyl ring, the phenyl ring is no longer nucleophilic enough ${ }^{40}$ to react with a second DMC molecule, making methyl 2,4-dimethoxybenzoate the only major sideproduct of this process.

\section{Effects of reaction conditions}

Amounts of DMC. Previous investigations on the reaction of catechol with DMC reported that in the presence of different catalysts $\left(\mathrm{KNO}_{3} / \mathrm{Al}_{2} \mathrm{O}_{3}\right.$ and $\mathrm{Mg}-\mathrm{Al}$ hydrotalcite), the mono- to bis-methylation selectivity was also affected by the reactants' molar ratio. ${ }^{10 g, 27}$ To explore this aspect in microwave-promoted methylations, additional experiments were carried out (conditions as per Table 2) by varying the amount of DMC (Table 3). Since one of the main objectives of this study was the optimisation of a $O$-methylation protocol mediated by DMC under MW conditions, it is noteworthy that the increase of the $\mathrm{DMC} /$ catechol molar ratio progressively enhanced the amount of veratrole up to the almost exclusive formation of this compound $(\sim 95 \%)$ at a $Q$ value $\geq 8.7$ (entries 3 and 4 , respectively). Thus, the higher the quantity of DMC, the better the conversion of catechol into the doubly $O$-methyl derivatives.

Amounts of DBU. At $160-170{ }^{\circ} \mathrm{C}$, the experiments of Table 2 indicated that a rather poor methylation selectivity was achieved for the reaction of resorcinol with DMC. In order to improve this result, the same process was investigated, not only at a higher temperature of $190{ }^{\circ} \mathrm{C}$, but also with different amounts of DBU (Fig. 6).

All reaction mixtures were heated until the conversions of resorcinol and compounds 2, 4 and 5 were complete. The increase of the DBU/1 ratio from 2 (one base equiv. per each $\mathrm{OH}$ group of 1) to 16, favoured the formation of the undesired product methyl 2,4-dimethoxybenzoate (7), the amount of which was progressively raised from 55 to $75 \%$. In all of these cases, compound 7 was the major product. By 
Table 3 Results of mono- and bis-methylation of catechol (2.73 $\mathrm{mmol}$ ) with different excess amount of DMC, DBU $(5.46 \mathrm{mmol})$ in $\mathrm{CH}_{3} \mathrm{CN}(3 \mathrm{~mL})$ at $160^{\circ} \mathrm{C}$. The reaction mixtures were heated for $40 \mathrm{~min}$ in an Anton Parr 300 focused microwave. Yield was determined by GC

\begin{tabular}{lllc}
\hline Entry & DMC/catechol ratio & Guaiacol/\% & Veratrole/\% \\
\hline 1 & 2.2 & 34.0 & 6.1 \\
2 & 4.4 & 47.6 & 28.4 \\
3 & 8.7 & 0.8 & 94.8 \\
4 & 13.1 & 0.3 & 94.9 \\
5 & 17.5 & 0 & 90.3 \\
\hline
\end{tabular}

contrast, if only 6.25 mol\% of DBU was used, the $O$-methylation selectivity improved significantly and 1,3-dimethoxybenzene (3) could be obtained in a yield as high as $84 \%$. This not only demonstrated that the relative amounts of DBU and resorcinol affected the product distribution of the reaction, but also that the base could be used in a catalytic amount.

An explanation for the observed variation in selectivity is offered by considering the properties of oxoanions of resorcinol. It should be noted that in water, at $25{ }^{\circ} \mathrm{C}$, the $\mathrm{p} K_{\mathrm{a}}$ values of resorcinol and the resorcinolate anion almost overlap (9.20 and 10.90). ${ }^{42}$ Therefore, the corresponding monodeprotonated and bis-deprotonated species are likely to coexist. Under non-aqueous conditions (as those used in this work), it is reasonable to assume that a similar equilibrium (but with a different equilibrium constant) exists among the mono- and di-anion of resorcinol. If so, when a high DBU/ substrate ratio is used, most of the resorcinol is bisdeprotonated. However, in the presence of a catalytic amount of DBU (6.25 mol\%), the mono oxoanion of resorcinol is almost exclusive formed. This species alone does not sufficiently activate the phenyl ring towards C-carboxylation, thereby hindering the formation of methyl 2,4-dimethoxybenzoate (7). As mentioned above, only in the bis-oxoanion of resorcinol, synergistic ortho/para directing/activating effects

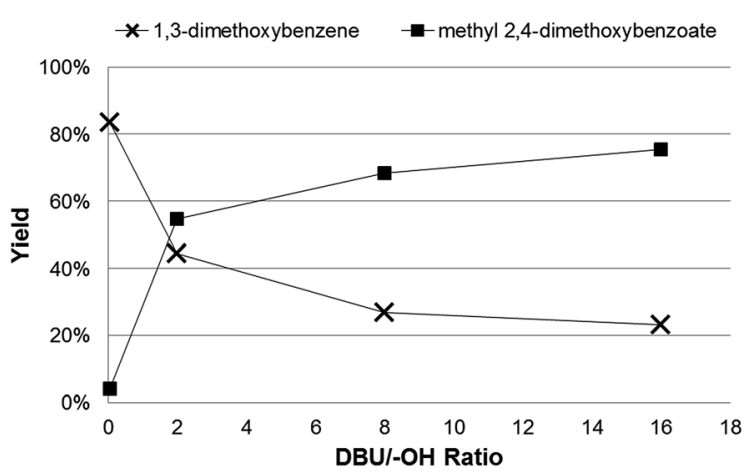

Fig. 6 The reaction of resorcinol $(2.73 \mathrm{mmol})$ with $\mathrm{DMC}(3 \mathrm{~mL})$ in the presence of different amounts of DBU. Experiments were carried out at $190{ }^{\circ} \mathrm{C}$ with $\mathrm{CH}_{3} \mathrm{CN}(3 \mathrm{~mL})$ as a solvent. Mixtures were heated for 10 min except for the reaction using a $\mathrm{DBU} /-\mathrm{OH}$ ratio of 0.0625 for which heating was prolonged up to $80 \mathrm{~min}$. Yield was determined by ${ }^{1} \mathrm{H}$ NMR (connecting lines as visual guide only). may operate to impart an unusually high reactivity of the 4and 6-positions of the aromatic ring.

\section{Other substrates}

The reaction conditions optimised for the methylation of phenol, catechol, hydroquinone and resorcinol, were then extended to the study of the $O$-methylation of several other DHBs as potential derivatives of the depolymerisation of the primary lignin network. ${ }^{12-24}$ In particular, the reaction of 4methylcatechol, 4-ethylcatechol, methylhydroquinone and 2,3dimethylhydroquinone with DMC were investigated at 160-170 ${ }^{\circ} \mathrm{C}$ with MW-heating and in the presence of DBU (Table 4). All substrates tested were converted into the corresponding bis-Omethylated products with excellent isolated yields (85-93\%), thus confirming the general efficacy of the proposed method.

\section{DBU as a catalyst}

Fig. 6 clearly demonstrated that DBU could be used in catalytic amounts with respect to resorcinol to achieve the corresponding $O$-bis-methyl derivative. These results perfectly match the general behavior of all DMC-mediated methylation reactions that are genuine catalytic processes (Scheme 1). To further investigate this aspect and fully prove the potential of the proposed protocol, additional experiments were carried out on the reaction of catechol and hydroquinone with DMC by using catalytic amounts of DBU. Results are reported in Table 5. For both catechol and hydroquinone, the decrease of the substrate/ DBU molar ratio to 4 or $8(12.5 \%$ and $6.25 \%$ molar equivalents of catalyst with respect to - $\mathrm{OH}$ groups, respectively) still facilitated the formation of the corresponding bis-methyl ethers in high yields (87-92\%, entries 3, 4, and 5). At the same time however, the temperature had to be increased from 160 to 180 and $190{ }^{\circ} \mathrm{C}$ to complete the reaction.

Shieh et al. suggested that DBU is not simply a base but also a nucleophilic catalyst which reacts with DMC to produce a more activated methylating agent (Fig. 3). ${ }^{10 e}$ Once the alkylation is complete, the methoxide ions generated can act as proton scavengers to liberate the protonated DBU and allow the reaction to proceed further. ${ }^{10 e}$ However, the methoxide ion itself may also act as a nucleophilic activator by converting the substrate into the corresponding oxoanion(s).

Table 4 Bis-methylation of dihydroxybenzene derivatives $(2.73 \mathrm{mmol}$ ) with DBU $(5.46 \mathrm{mmol}), \mathrm{DMC}(3 \mathrm{~mL})$ in $\mathrm{CH}_{3} \mathrm{CN}(3 \mathrm{~mL})$

\begin{tabular}{lllll}
\hline Entry & Substrate & $\begin{array}{l}\text { Time/ } \\
\min \end{array}$ & $\begin{array}{l}\text { Temp/ } \\
{ }^{\circ} \mathrm{C}\end{array}$ & $\begin{array}{l}\text { Bis-methylated } \\
\text { product/\% }{ }^{a}\end{array}$ \\
\hline 1 & Catechol & 60 & 160 & 90 \\
2 & 4-Methylcatechol & 60 & 160 & 91 \\
3 & 4-Ethylcatechol & 60 & 160 & 92 \\
4 & Hydroquinone & 40 & 170 & 90 \\
5 & Methylhydroquinone & 60 & 170 & 85 \\
6 & 2,3-Dimethylhydroquinone & 60 & 170 & 93 \\
${ }^{a}$ Isolated yield. & & &
\end{tabular}


Table 5 Results of mono- and bis-methylation of dihydroxybenzene derivatives $(2.73 \mathrm{mmol}$ ) with catalytic amounts of DBU, DMC ( $3 \mathrm{~mL})$ in $\mathrm{CH}_{3} \mathrm{CN}(3 \mathrm{~mL})$. The reaction mixtures were heated for $80 \mathrm{~min}$ in an Anton Parr 300 focused microwave. Yield was determined by GC

\begin{tabular}{lllllr}
\hline Entry & Substrate & Substrate/DBU $(\mathrm{mol} / \mathrm{mol})$ & Temp $/{ }^{\circ} \mathrm{C}$ & Mono-methylated product/\% & Bis-methylated product/\% \\
\hline 1 & Catechol & 60 & 170 & 49.5 & 1.8 \\
2 & Catechol & 60 & 180 & 0 & 92.4 \\
3 & Catechol & 60 & 180 & 33.9 & 0.7 \\
4 & Catechol & 40 & 190 & 0 & 90.1 \\
5 & Hydroquinone & 60 & 190 & 0 & 87.2 \\
\hline
\end{tabular}

\section{Conclusions}

A method for the bis-O-methylation of a series of dihydroxybenzene derivatives has been developed by using dimethyl carbonate as a green reagent in a focused microwave reactor. Excellent isolated yields (up to 93\%) have been achieved for the corresponding ether products. Overall, the procedure represents an efficient approach for the upgrading of lignin building blocks, especially 1,2-dihydroxybenzene and 1,4-dihydroxybenzene derivatives, that can be selectively converted under relatively mild conditions with DBU as an inexpensive catalyst.

Additional studies directed at expanding the scope of this transformation, for example the conversion of dihydroxybenzenes with higher alkyl carbonates, the methylation of mixtures of such derivatives generated by HTU of lignocellulosic biomass, and the application of a flow microwave reactor for these processes will be the subject of future investigations.

\section{Acknowledgements}

The authors thank the Science and Industry Endowment Fund (SIEF) (Grant no. RP03-028) for partial financial support for this research, JNGS acknowledges the receipt of an Australian Postgraduate Award, and we thank Dr Alex Yuen for valuable discussions.

\section{References}

1 P. Tundo and M. Selva, Acc. Chem. Res., 2002, 35, 706.

2 B. Schaffner, F. Schaffner, S. P. Verevkin and A. Borner, Chem. Rev., 2010, 110, 4554.

3 U. Romano, F. Rivetti and N. Di Muzio, Anic S.p.A., US Pat., US4318862(A), 1982.

4 K. Nishhira, K. Mizutare and S. Tanaka, UBE Industries, Japan, US Pat., US5162563(A), 1992.

5 S. Fukuoka, I. Fukawa, M. Tojo, K. Oonishi, H. Hachiya, M. Aminaka, K. Hasegawa and K. Komiya, Catal. Surv. Asia, 2010, 14, 146.

6 (a) M. Selva, P. Tundo, A. Perosa and F. Dall'Acqua, J. Org. Chem., 2005, 70, 2771; (b) M. Selva, Pure Appl. Chem., 2007, 79(11), 1855.

7 M. Selva and A. Perosa, Green Chem., 2008, 10, 457.

8 (a) C. O. Kappe, Chem. Soc. Rev., 2008, 37, 1127; (b)

C. O. Kappe, Angew. Chem., Int. Ed., 2004, 43, 6250; (c)

C. O. Kappe and D. Dallinger, Chem. Rev., 2007, 107, 2563.
9 (a) N. Kuhnert, Angew. Chem., Int. Ed., 2002, 41, 1863; (b) M. A. Herrero, J. M. Kremsner and C. O. Kappe, J. Org. Chem., 2008, 73, 36; (c) C. O. Kappe, B. Pieber and D. Dallinger, Angew. Chem., Int. Ed., 2013, 52, 1088.

10 (a) G. Barcelo, D. Grenouillat, J.-P. Senet and G. Sennyey, Tetrahedron, 1990, 46, 1839; (b) Y. Lee and I. Shimizu, Synlett, 1998, 1063; (c) S. Ouk, S. Thiébaud, E. Borredon and P. Le Garrs, Green Chem., 2002, 4, 431; (d) F. Rajabi and M. R. Saidi, Synth. Commun., 2004, 34, 4179; (e) W. Shieh, S. Dell and O. Repič, Org. Lett., 2001, 3(26), 4279; (f) U. Tilstam, Org. Process Res. Dev., 2012, 16, 1150; $(g)$ U. Tilstam, Org. Process Res. Dev., 2012, 16, 1974; (h) P. Tundo, F. Trotta, G. Moraglio and F. Ligorati, Ind. Eng. Chem. Res., 1988, 27, 1565; (i) A. Bomben, M. Selva and P. Tundo, Ind. Eng. Chem. Res., 1999, 38, 2075; (j) M. Selva, E. Militello and M. Fabris, Green Chem., 2008, 10, 73; $(k)$ T. N. Glasnov, J. D. Holbrey, C. L. Kappe, K. R. Seddon and T. Yan, Green Chem., 2012, 14, 3071.

11 P. Tundo, L. Rossi and A. Loris, J. Org. Chem., 2005, 70, 2219. 12 (a) R. Beauchet, F. Monteil-Rivera and J. M. Lavoie, Bioresour. Technol., 2012, 121, 328; (b) H. Pińkowska and P. Wolak, Fuel, 2013, 113, 340; (c) A. Toledano, L. Serrano and J. Labidi, Fuel, 2014, 116, 617; (d) R. Katahira, A. Mittal, K. McKinney, X. Chen, M. P. Tucker, D. K. Johnson and G. T. Beckham, ACS Sustainable Chem. Eng., 2016, 4, 1474.

13 M. Garcia-Perez, S. Wang, J. Shen, M. Rhodes, W. J. Lee and C.-Z. Li, Energy Fuels, 2008, 22, 2022.

14 S. I. Yang, M. S. Woo and C. Y. Woo, Energy, 2014, 66, 162. 15 N. Chatterjee, H.-J. Eom, S.-H. Jung, J.-S. Kim and J. Choi, Environ. Toxicol., 2014, 29, 1409.

16 G. Yildiza, F. Ronssea, R. Venderboschb, R. van Durenc, S. R. A. Kerstend and W. Prinsa, Appl. Catal., B, 2015, 168169, 203.

17 K. Sipilaè, E. Kuoppala, L. Fagernaès and A. Oasmaa, Biomass Bioenergy, 1998, 14, 103.

18 Y. Yu, Y. Zeng, J. Zuo, F. Ma, X. Yang, X. Zhang and Y. Wang, Bioresour. Technol., 2013, 134, 198.

19 H. Zhang, Y.-T. Cheng, T. P. Vispute, R. Xiao and G. W. Huber, Energy Environ. Sci., 2011, 4, 2297.

20 S. Karagöz, T. Bhaskar, A. Muto and Y. Sakata, Bioresour. Technol., 2006, 97, 90.

21 R. D. Barrows and D. C. Elliott, Fuel, 1984, 63, 4.

22 A. Aho, N. Kumar, A. V. Nashkul, K. Eränen, M. Ziolek, P. Decyk, T. Salmi, B. Holmbom, M. Hupa and D. Yu Murzin, Fuel, 2010, 89, 1992. 
23 S. Karagöz, T. Bhaskar, A. Muto, Y. Sakata, T. Oshiki and T. Kishimoto, Chem. Eng. J., 2005, 108, 127.

24 S. Karagöz, T. Bhaskar, A. Muto and Y. Sakata, Fuel, 2004, 83, 2293.

25 E. Fuhrmann and J. Talbiersky, Org. Process Res. Dev., 2005, 9, 206.

26 P. Tundo, in Continuous-flow Methods in Organic Synthesis, Ellis Horwood Ltd, Chichester (UK), 1st edn, 1996.

27 (a) S. Ratton, Rhone-Poulenc Industries, US Pat., 4487975, 1984; (b) Y. Fu, T. Baba and Y. Ono, Appl. Catal., A, 1998, 166, 419; (c) Y. Fu, T. Baba and Y. Ono, Appl. Catal., A, 1998, 166, 425; (d) Y. Fu, T. Baba and Y. Ono, Appl. Catal., A, 1999, 178, 219; (e) Y. Fu, T. Baba and Y. Ono, Appl. Catal., A, 1999, 176, 201; $(f)$ T. M. Jyothi, T. Raja, M. B. Talawar, K. Sreekumar, S. Sugunan and B. S. Rao, Synth. Commun., 2000, 30(21), 3929; (g) T. M. Jyothi, T. Raja, M. B. Talawar and B. S. Rao, Appl. Catal., A, 2001, 211, 41; (h) Z. L. Shen, X. Z. Jiang, W. M. Mo, B. X. Hu and N. Sun, Green Chem., 2005, 7, 97; (i) M. Vijayaraj and C. S. Gopinath, J. Catal., 2006, 243, 376; (j) A. Dhakshinamoorthy, A. Sharmila and K. Pitchumani, Chem.-Eur. J., 2010, 16, 1128.

28 (a) A. Loupy, J. Sansoulet and F. Vaziri-Zand, Bull. Soc. Chim. Fr., 1987, 1027; (b) J. C. Lee, J. Y. Yuk and S. H. Choi, Synth. Commun., 1995, 25, 1367; (c) P. M. Paduraru, R. T. W. Popoff, R. Nair, R. Gries, G. Gries and E. Plettner, J. Comb. Chem., 2008, 10, 123; (d) J. J. V. Eynde and I. Mailleux, Synth. Commun., 2001, 37, 1; (e) B. Behrmand, F. Molin and H. Gallardo, Dyes Pigm., 2012, 95, 600; (f) P. J. Reddy, A. S. Reddy, J. S. Yadav and B. V. S. Reddy, Tetrahedron Lett., 2012, 53, 4051; (g) V. Karunakaran, D. D. Prabhu and S. Das, J. Phys. Chem. C, 2013, 117, 9404.

29 (a) W. H. Perkin Jr and C. Weizmann, J. Chem. Soc., Trans., 1906, 89, 1649; (b) E. H. Vickery, L. F. Pahler and E. J. Eisenbraun, J. Org. Chem., 1979, 44(24), 4444; (c) J. Zhang, Y. Cui, M. Wang and J. Liu, Chem. Commun., 2002, 2526; (d) A. R. Massah, M. Mosharafian, A. R. Momeni, H. Aliyan, H. J. Naghash and M. Adibnejad, Synth. Commun., 2007, 37, 1807; (e) S. O. Mihigo, W. Mammo, M. Bezabih and K. Andrae-Marobela, Bioorg. Med. Chem., 2010, 18, 2464; $(f)$ U. S. Hiremath, Tetrahedron
Lett., 2013, 54, 3419; $(g)$ H. Singh, A. Balamurugan and M. Jayakannan, ACS Appl. Mater. Interfaces, 2013, 5, 5578.

30 (a) K. Bauer, R. Molleken and R. Hopp, Haarmann \& Reimer GmbH, US Pat., US3895076(A), 1975; (b) G. T. McCloud, M. R. Brimer and C. L. Gibson, Eastman Kodak Company, US Pat., US3911022(A), 1975; (c) S. Porchet, S. Su, R. Doepper and A. Renken, Chem. Eng. Technol., 1994, 17, 108; (d) S. C. Lee, S. W. Lee, K. S. Kim, T. J. Lee, D. H. Kim and J. C. Kim, Catal. Today, 1998, 44, 253; (e) V. Vishwanathan, S. Ndou, L. Sikhwivhilu, N. Plint, K. V. Raghavan and N. J. Coville, Chem. Commun., 2001, 893; (f) R. Bal, S. Mayadevi and S. Sivasanker, Org. Process Res. Dev., 2003, 7, 17; (g) X. Zhu, X. Li, M. Jia, G. Liu, W. Zhang and D. Jiang, Appl. Catal., A, 2005, 282, 155; (h) X. Zhu, X. Li, X. Zou, Y. Wang, M. Jia and W. Zhang, Catal. Commun., 2006, 7, 579; (i) X. Liao, Z. Zhou, Z. Wang, X. Zou, G. Liu, M. Jia and W. Zhang, J. Colloid Interface Sci., 2007, 308, 176; (j) A. A. Jafari, A. Khodadadi and Y. Mortazavi, J. Mol. Catal. A: Chem., 2013, 372, 79.

31 P. Belov, V. L. Campanella, A. W. Smith and R. Priefer, Tetrahedron Lett., 2011, 52, 2776.

32 J. N. G. Stanley, M. Selva, A. F. Masters, T. Maschmeyer and A. Perosa, Green Chem., 2013, 15, 3195.

33 D. W. Robertson, E. E. Beedle, J. H. Krushinski, G. D. Pollock, H. Wilson, V. L. Wyss and J. S. Hayes, J. Med. Chem., 1985, 28, 717.

34 Y. Zhou, J. Wu and E. W. Lemmon, J. Phys. Chem. Ref. Data, 2011, 40(4), 043106.

35 W. V. Steele, R. D. Chirico, S. E. Knipmeyer, A. Nguyen and N. K. Smith, J. Chem. Eng. Data, 1997, 42(6), 1037.

36 E. E. Walker, J. Appl. Chem., 1952, 2, 470.

37 W. H. Walker, A. R. Collett and C. L. Lazzell, J. Phys. Chem., 1931, 35, 3259.

38 M. Carafa, E. Mesto and E. Quaranta, Eur. J. Org. Chem., 2011, 2458.

39 Y. Ji, J. Sweeney, J. Zoglio and D. Gorin, J. Org. Chem., 2013, 78, 11606.

40 C. Hansch, A. Leo and R. W. Taft, Chem. Rev., 1991, 91, 165. 41 R. F. W. Bader and C. Chang, J. Phys. Chem., 1989, 93, 2946. 42 S. E. Blanco, M. C. Almandoz and F. H. Ferretti, Spectrochim. Acta, Part A, 2005, 61, 93. 